\title{
Water Balance Modeling For Efficient Water Management in Canal Command
}

\author{
Md. Masood Ahmad, Mazhar Eqbal, Amit Kumar, \\ Joint Director \& Head Dept of Civil Engg. * \\ Asst Prof, Dept of Computer Sc \& Engg. * \\ Asst Prof, Dept of Civil Engg. * \\ * Maulana Azad College of Engg \& Technology, Patna, Bihar (India)
}

\begin{abstract}
A water balance model for efficient water management in canal command area is developed to provide demand-based water release strategies for reducing the gap between canal supplies and demands and to help irrigation engineers, agronomics and agro-meteorologist in planning, operation and management of irrigation system efficiently. The Patna canal network of the Sone Irrigation Project in India is used as a case study. This study estimates the demand at the head of the distributaries of the canal network in advance for each irrigation cycle using historical weather data, weather forecast and crop \& soil conditions. This simulation combined with strong agronomic knowledge and judgment provides a powerful impact on the overall water management strategy to be adopted in the command area of the irrigation project.
\end{abstract}

Keywords: Canal supplies and demand, Evapotranspiration, Irrigation, Rainfall, Rice, Water balance model, Water management.

\section{Introduction}

Societies are facing major challenges in allocating water resources to growing water demands due to population growth and industrial \& agricultural developments. With increasing water scarcity, the need to increase agricultural water productivity is receiving significant attention in developing countries. Among alternative options for meeting increasing water demand, improving productivity has received considerable attention. Therefore, planning of water system to face future development conditions needs further studies on land, water use, and resources as well as consideration of objectives to maximize crop production to achieve the maximum net return.

The creation of a number of large irrigation system in India contributed significantly in increasing in food production provided by the Green Revolution. It also improved food security in the region and reduced the dependence of agriculture on the vagaries of the monsoon. However, the increasing costs of creation and maintenance of these systems, and doubts about the long-term sustainability of the soil and water resources in their command areas, have led to much concern. This relates mainly to the low operational efficiencies of the large system (ranging between 30 and $40 \%$ ), and consequent water losses in transmission and low crop yields. The operation of large canal irrigation system is a complex task. In the major irrigation system of India, water is delivered over a large area (10,000 to a million hectares or more in India) with spatially variable soils, crops and weather conditions. The irrigation supplies reach the fields through a hierarchical network of main canals, branch canals (secondary canals) and distributaries (tertiary canals). The distributary is usually the last point of control for main irrigation system management as down-stream of this level, irrigation is either field-to-field or under the direct control of the farmers. The irrigation supplies into each distributary are decided based on the estimated water demands of the crops in the area irrigated by it, after accounting for field-application losses. The demands depend on soil, weather and crop conditions in the irrigated area. Further, the total areas irrigated by different distributaries also vary. The irrigation demand estimation for each distributary is therefore independent of other distributaries. The individual distributary-level water demands are aggregated to assess irrigation supply requirements at higher levels (branch canals and main canals) of the irrigation system after accounting for transmission losses. The operational efficiencies depend on the extent to which the irrigation supplies match the demands at each hierarchical level of the network. Thus estimating periodically, and in real time, the water demands of individual distributaries of the canal network are critical for improving the overall operational efficiencies of large irrigation system.

Most of the major irrigation command areas in India suffer from problems of inadequate and unreliable water supply, having wide gaps between irrigation potential created and utilized.This leads to temporal imbalance of water demands and supplies, excessive seepage losses and rise of ground -water table, resulting in problems of water logging and salinity. In addition, failure of monsoon rains, resulting in water scarcity and drought lead to disputes among the water users. All these problems exist due to inadequate attention paid to the assessment of water resources, non-matching of canal water releases with rainfall, crop water requirements and 
change in the cropping pattern from what has been envisaged at the time of planning. While short-term imbalances between water supplies and demands are inevitable, it is possible to reduce these considerably, if not totally, through development and adoption of appropriate water-management techniques and policies that take into account rainfall, changing cropping pattern and crop water demands. Almost all the current canal waterrelease policies in India (warabandi, shejpali, block system, localized system and zonal system) are supplybased and make little effort in meeting the actual water requirement of the existing cropping pattern and under actual level of ground-water exploitation. Optimization and simulation models were developed for providing operation policies for large system to reduce the gap between the demands and supplies. Optimization models provide operational guidelines; however, they do not incorporate heuristic, subjective and judgmental information, which is also needed for efficient operation of a water resource system. Optimization models are not user-friendly and work on several assumptions. The concept of water balance simulation model is one of the greatest advances in understanding the response of crops in water limited environments. In existing irrigation systems, the proper estimation of different components of water requirements in the field i.e. evapotranspiration, percolation and runoff, can lead to effective use of the available water resources and to optimize land areas cultivated with limited amounts of irrigation water. The water balance components can be quantified through field experiments but it is often not used because of the excessive time and expenditure involved in the execution. Hence simulation models are being increasingly used in soil-water-crop relationships research.

\section{Study Area}

The case study area forms a part of the Sone irrigation project in Bihar (India) known as Patna main canal (fig.1 \& 2) which extend over $70 \mathrm{~km}$ and irrigates nearly 1,90,000 hect through a network of 40 distributaries. The study area is bounded by the river Sone on the west, river Punpun on the east and the river Ganga in the north. The area irrigated by each distributaries range from 200 to 25,000 hectare. The distributaries operate 10 days on and 5 days off cycle during Monsoon (Kharif) season. As per the information received from Water Resource Dept. Govt of Bihar (India), during the Monsoon (Kharif) season, the Patna main canal opens on 25th May and closes on 25th October.

The area receives about $1100 \mathrm{~mm}$ of rain, over $80 \%$ of which occurs over the Monsoon season (June to Sept).Soils are alluvial and vary from light to heavy textured clays, usually clay loam.

Rice is the main crop grown in the area in Monsoon (Kharif) season. Rice is a semi-aquatic plant which requires about $150 \mathrm{~mm}$ depth of standing water in the field during transplanting. The high irrigation requirements at transplanting and the limited channel capacity lead to staggering of the transplanting activities over the command area of the distributaries. A staggering period of approx two weeks (15 days) during mid or late June to August is usually considered to coincide with irrigation cycle. This system leads to rice crop at different stages of development depending on the date of transplantation. This results variable water standing conditions in different rice fields irrigated by a distributary during any irrigation cycle.

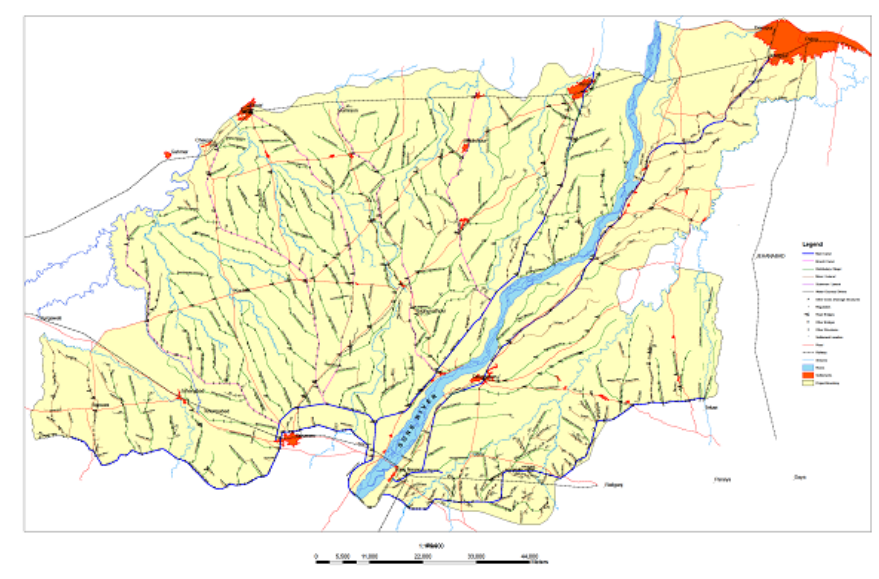

Fig:-1 Sone Command area Satellite map. 


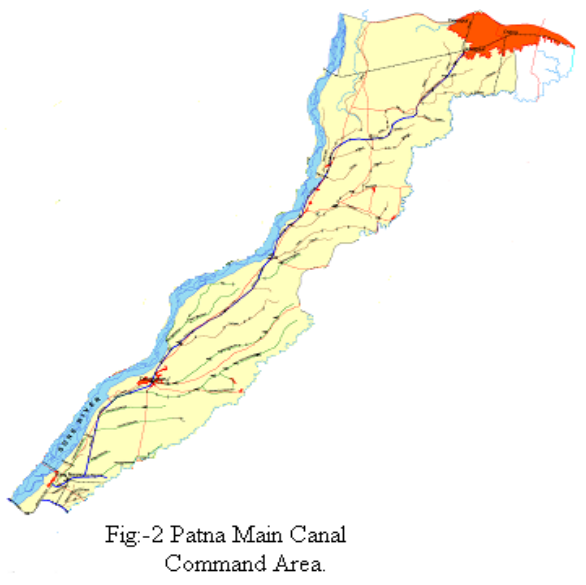

III. Methodology

The generalized water balance model will be governed by following eqs -

$$
[\mathrm{DW}]_{\mathrm{t}}=[\mathrm{DW}]_{\mathrm{t}-1}+[\mathrm{RFV}]_{\mathrm{t}}+[\mathrm{IW}]_{\mathrm{t}}-[\mathrm{ET}]_{\mathrm{t}}-[\mathrm{P}]_{\mathrm{t}}-[\mathrm{Q}]_{\mathrm{t}}
$$

Where,

$[D W] t=$ Depth of water in the field at the end of day

$[D W] t_{-1}=$ Depth of water in the field at the beginning of day

$[\mathrm{RFV}] \mathrm{t}=$ Rainfall during the day

$[I W] \mathrm{t}=$ Irrigation water applied in the field during the day

$[\mathrm{ET}] \mathrm{t}=$ Evapotranspiration during the day

$[\mathrm{P}]_{\mathrm{t}}=$ Percolation during the day

$[Q]_{t}=$ Runoff during the day

$[\mathrm{Q}]_{\mathrm{t}}=[\mathrm{RFV}]_{\mathrm{t}}+[\mathrm{DW}]_{\mathrm{t}-1}-[\mathrm{BH}]$

Where $[\mathrm{BH}]=$ Bund Height

The above components are expressed in depth $(\mathrm{mm})$ and the time period is considered as one day. The component of the water balance model for a rice field as shown in fig: 3

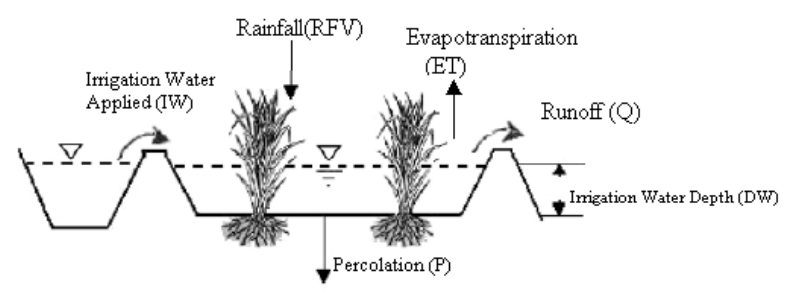

Fig:-3 Water Balance Components of the Model

The methodological workflow of model is given in fig(4).

The conditions for solving the model as per general and agronomics practices for rice crop which were considered in this case study, are as follows -

** At the transplanting date $150 \mathrm{~mm}$ water is applied to the field with the condition that the sum of applied water and rainfall on that day should not be more than the bund height. The bund height is taken as $150 \mathrm{~mm}$, i.e.

If $[\mathrm{IW}]+[\mathrm{RFV}] \geq[\mathrm{BH}]$

Or, $[\mathrm{IW}]+[\mathrm{RFV}] \geq 150$

Then, $[\mathrm{IW}]=[\mathrm{BH}]-[\mathrm{RFV}]$

Otherwise, $[\mathrm{IW}]=150$

The initial depth of the water in the field is taken as Zero.

The runoff $[\mathrm{Q}]_{\mathrm{t}}$ is to be calculated as

** If $[\mathrm{Q}]_{\mathrm{t}} \leq 0$ from eq (2)

Then $[\mathrm{Q}]_{\mathrm{t}}=0$ Otherwise $[\mathrm{Q}]_{\mathrm{t}}=[\mathrm{Q}]_{\mathrm{t}}$

$* *$ If the depth of water at the beginning of any day is less than $10 \mathrm{~mm}$ then on that day irrigation water of $50 \mathrm{~mm}$ should be applied in the field, i.e.

If $[\mathrm{DW}] \mathrm{t} \leq 10$.

Then $[\mathrm{IW}] \mathrm{t}_{+1}=50$ 
Otherwise $[\mathrm{IW}] \mathrm{t}_{+1}=0$

** On $45,46 \& 47^{\text {th }}$ day from the day of transplantation, all water from the field should be drained out for efficient supply of nutrients to the crop and effective weed control in field. Standing water depth at the beginning of these days and rainfall which occurs during these days is treated as runoff. Therefore on $48^{\text {th }}$ day, irrigation water of $50 \mathrm{~mm}$ must be supplied.

** Duration of each crop is taken as 120 days. After $105^{\text {th }}$ day no water is applied to the field as this is the maturing period of the crop before harvesting.

** The depth of water in the field after running the eq (1) \& (2) will be available for each day during the duration of the crop.

** The irrigation water applied in the field is taken as sum of irrigation water applied during one cycle. One cycle constitutes 15 days. Therefore for each crop there will be 8 cycle $(=120 / 15)$. Finally we have to find out sum of irrigation water applied to the field in each cycle for all the crops. In this case study there is four crops (Rice1, Rice2, Rice3 \& Rice4), the transplantation date of each crop lags by one cycle I.e. 15 days and each crop covers $25 \%$ of the command area. The rice transplanted on different dates needs to be treated as different crops for running the water balance model as there are four transplanting dates.

The input data required for running the model are summarized in Table 1. Evapotranspiration (ET) is calculated using the FAO-Penman Monteith Method (FAO CROPWAT-8) using the 50 years weather data (1951-2000) of the study area collected from IMD, Govt of India. Percolation rate (P) for clay loam soil usually varies from $2-3 \mathrm{~mm} /$ day. For the case study area, this value is calculated using FAO CROPWAT-8. Daily rainfall data for a period of 49 Years from 1960 -2008 were obtained from IMD Govt of India. The model was run by using the rainfall data of year 2008 and Patna Distributary of Patna main canal which has a command area 876 hect is selected.

\section{Table 1. Input data for water balance model}

- Name of the selected distributary

- Daily rainfall for each raingauge station (mm)

- Forecast rainfall

- Transplanting date (day and month)

- Number of transplanting dates

- Crop duration (days)

- Bund height (mm)

- Days to cut-off date of irrigation

- Soil type. 


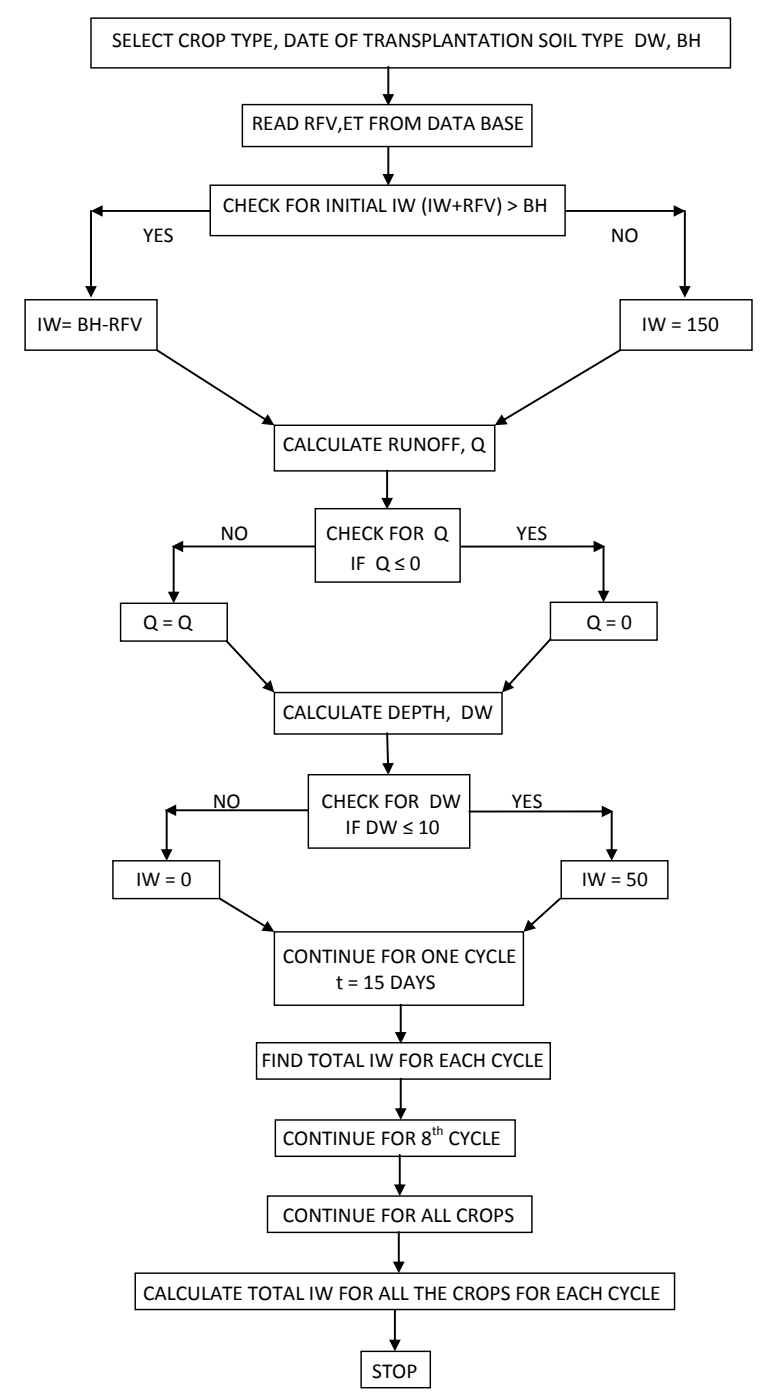

Fig:-4 Schematic diagram of the workflow of Model

\section{Results and Discussion}

The model was run at daily time step with rainfall, soil and crops data to get the water status in field and required water release in each cycle. To illustrate the model, daily historical data of rainfall of year 2008 was used and result was shown in fig 5,6\&7. The demand of water varies significantly over the different irrigation cycle. In some cycle, demand is more than design capacity of the distributary. In such periods, there may be a need to prioritize water allocations among the crops in the area irrigated by the distributary.

The same model is also to be run with the medium range forecasted rainfall to get the information regarding the water release requirement in each cycle in advance. The IMD usually provides medium range (5-7 days ahead) weather forecast. The use of this forecast will not alter the model development and application presented above in any way. The only change is to the input data of rainfall (forecasted data) instead of historical rainfall data.

In the field usually the water resource managers face the operational problem in respect of estimating the irrigation requirements at the level of each distributary at the beginning of every irrigation cycle. In the absence of knowledge of irrigation release required in each cycle, either they supply less quantity or in excess of the requirements. Hence often they fail to meet the water demands particularly in the event of low rainfall year. This model helps a lot to the water resource managers to know in advance water release required during each cycle and with this knowledge the water can be conserved in the reservoir during low demand period and the same can be released during high demand period and also can used for the winter season crops which are planted after the harvest of rice. 


\section{Conclusions}

The success of good water management lies in applying the required amount of water at the right time and at the right place and also its proper performance evaluation. The model presented here can help in improving the management of water allocation systems and monitoring of water distribution system in existing Sone canal command scheme.

\section{References}

[1]. Allen R G, Pereira L S, Dirk R, Martin S . Crop Evapotranspiration; Guidelines for computing crop water requirements, FAO Irrigation and Drainage, Rome, 1998; Paper No-56.

[2]. Biswas A K, considerations for sustainable irrigation development in Asia, Water Resource Dev.1994, 10(4) p 457-474.

[3]. Burt C M and Gartrell G, Irrigation Canal-Simulation Model Usage, Journal of irrigation and Drainage Engg, ASCE 1993 Vol.119 No. 4 July/Aug p 631-636.

[4]. Dantane N G, Effective rainfall in irrigated agriculture, Irrigation and Drainage paper No 25, FAO Rome Italy, 1974

[5]. Ghahramn B, Sepaskhah A R, Optimal allocation of water from a single purpose reservoir to an irrigation project with predetermined multiple cropping patterns, journal of irrigation Sc. 2002, 21 p 127-137.

[6]. Hajilal M S, Rao N H, Sarma P B S, Real time irrigation reservoir operation, Agriculture Water Management 1998, 38 p 103-122.

[7]. Lorite I J, Mateos, Fereres E, Impact of spatial and temporal aggregation of input parameters on the assessment of irrigation scheme performance, Journal of Hydrology 2005,300 p 286-299.

[8]. Majumdar P P, Teegavarapu R, Short term reservoir operation model for multicrop irrigation, Journal of Hydrological Sc $199843 \mathrm{p}$ $479-494$

[9]. Singh D K, Jaiswal C S, Reddy K S, Singh R M, Bhandrakar D M, Optimal cropping pattern in a canal command area, Journal of Agriculture Water Management 200150 p1-8.

[10]. Vedula S, Majumdar P P, Optimal reservoir for irrigation of multiple crops, Journal of Water Resource Research 199228 p $1-9$

\section{$\underline{\text { Appendix }}$}

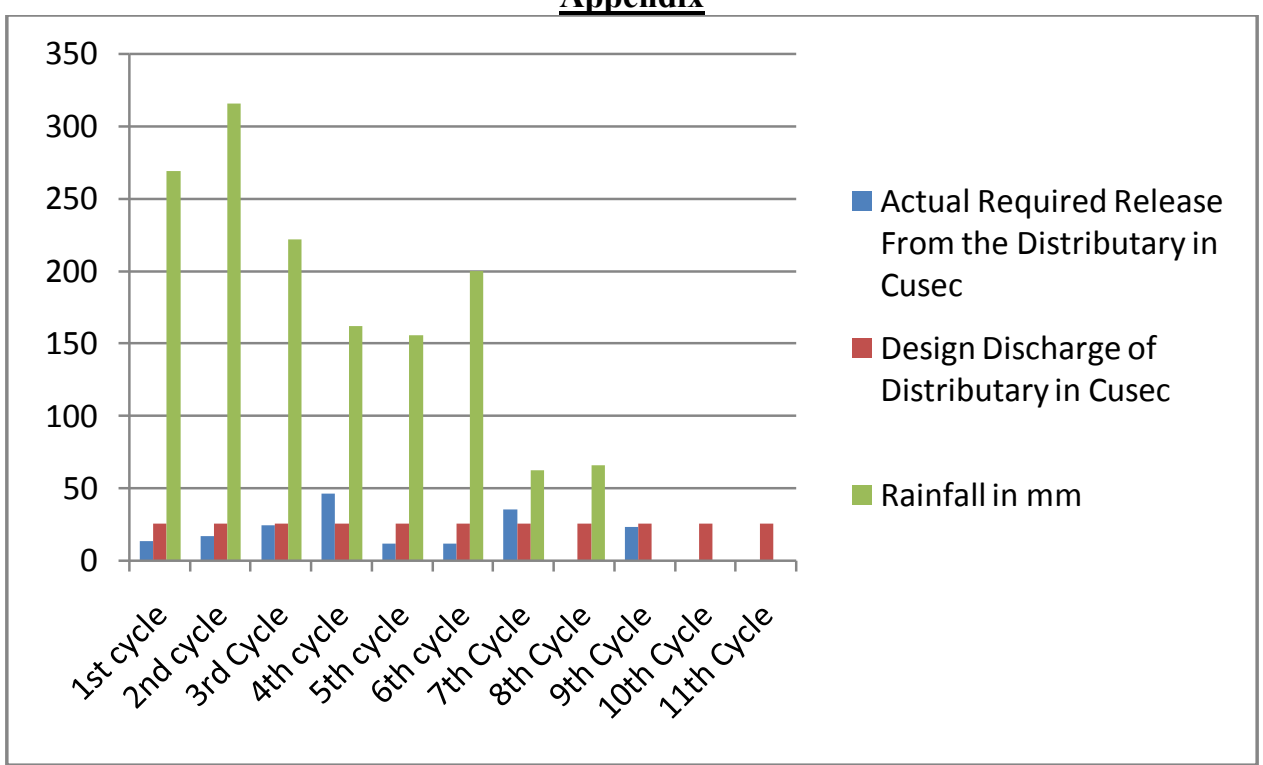

Fig:-4 Required irrigation releases for Patna Distributary in different irrigation cycle.

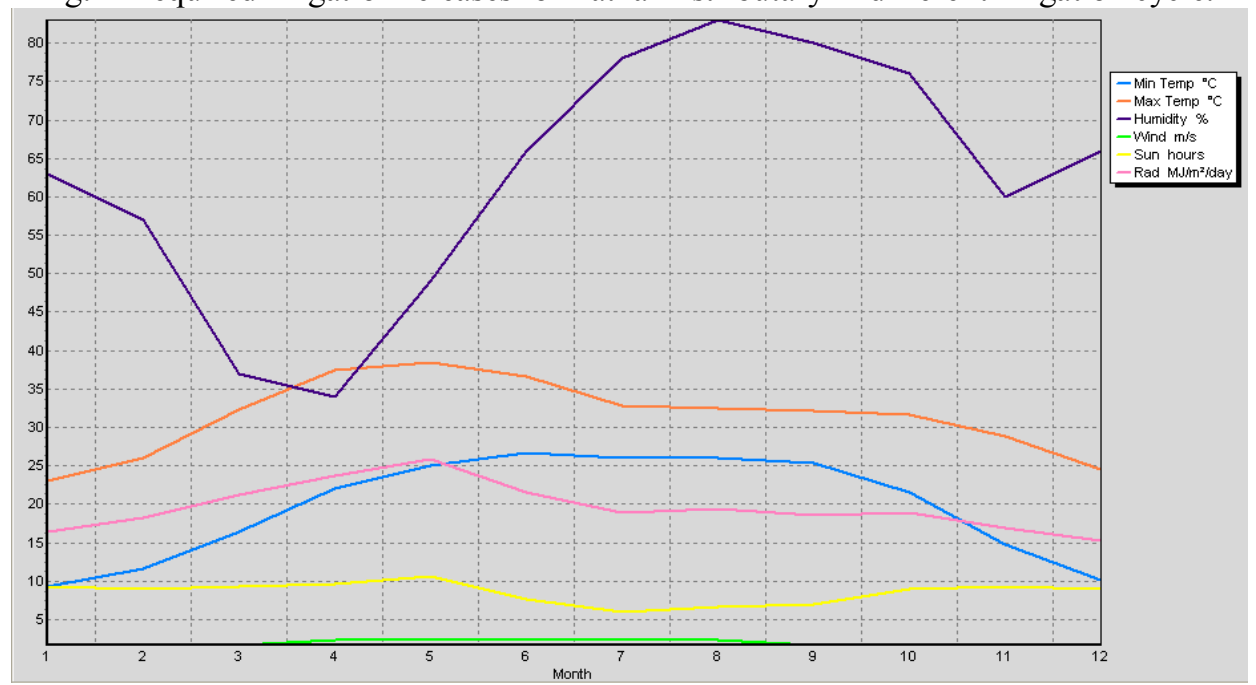

Fig:-5 Climatic weather data for Patna 


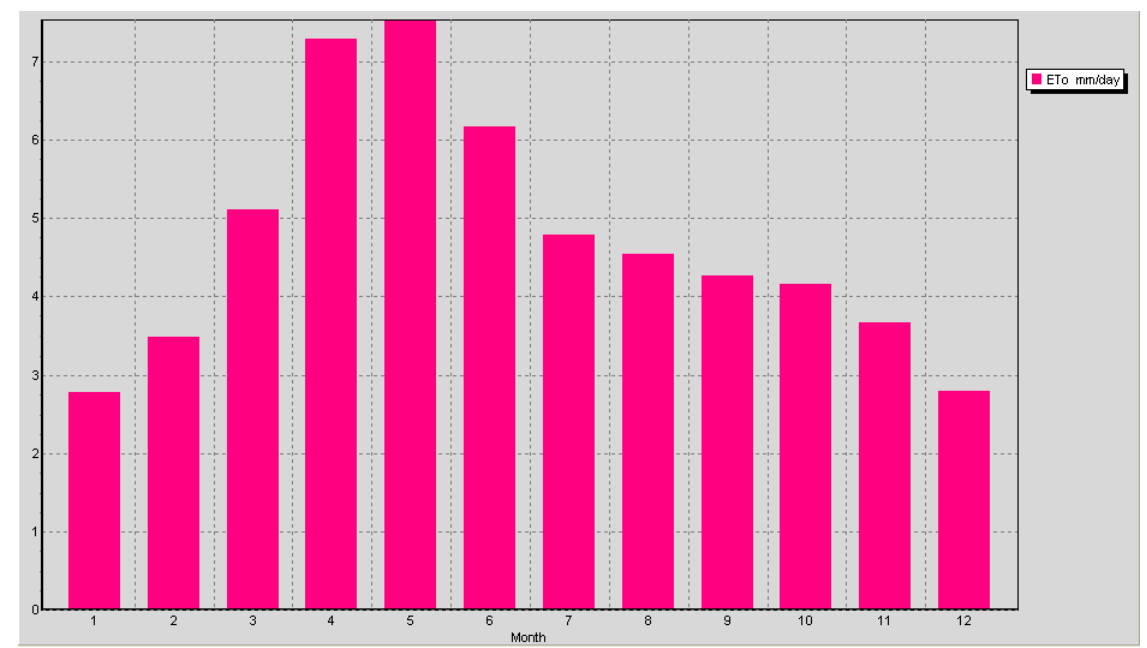

Fig:-6 Monthly ET Value calculated for Patna 